\title{
Pactos do sensível
}

\author{
HENZ, Alexandre de Oliveira ${ }^{1}$ \\ RODRIGUES, André ${ }^{2}$ \\ CAPOZZOLO, Angela Aparecida ${ }^{3}$ \\ MORENO, Harete Vianna ${ }^{4}$ \\ $B A L D O$, Rafaela Camargo ${ }^{5}$ \\ CASETTO, Sidnei José6
}

\section{RESUMO}

Este artigo apresenta experiências sensíveis relacionadas com o Laboratório de Sensibilidades da UNIFESP, com a formação e o trabalho em saúde. A partir de narrativas, produzidas pelos integrantes do GELS (grupo de estudos do Laboratório de Sensibilidades), foi possível desdobrar experiências e apostas que constituem dispositivos de formação, nem sempre com objetivos

\footnotetext{
${ }^{1}$ Doutor em Psicologia Clínica na Pontifícia Universidade Católica de São Paulo, professor do departamento de Saúde, Clínica e Instituições da Universidade Federal de São Paulo (UNIFESP), pesquisador do Laboratório de Estudos e Pesquisas em Formação e Trabalho em Saúde (LEPETS) e do Laboratório de Sensibilidades. Email: alexandrehenz2000@yahoo.com.br. Lattes: http://lattes.cnpq.br/8635317893278680. Orcid: https://orcid.org/0000-0002-6079-1938.

${ }^{2}$ Doutorando da Faculdade de Saúde Pública da Universidade de São Paulo (FSP/USP). Pesquisador do Laboratório de Estudos e Pesquisas em Formação e Trabalho em Saúde (LEPETS), do Laboratório de Sensibilidades (UNIFESP) e do grupo Micropolítica e Saúde (FSP/USP). Email: dreepsico@hotmail.com. Lattes: http://lattes.cnpq.br/6894336079264122. Orcid: https://orcid.org/0000-0003-1988-569.

${ }^{3}$ Doutora em Saúde Coletiva também pela Faculdade de Ciências Médicas da Universidade Estadual de Campinas. Professora do departamento de Saúde, Clínica e Instituições da Universidade Federal de São Paulo (UNIFESP), pesquisadora do Laboratório de Estudos e Pesquisas em Formação e Trabalho em Saúde (LEPETS) e do Laboratório de Sensibilidades. Email: angeruma@uol.com.br. Lattes: http://lattes.cnpq.br/7660336218859464. Orcid: https://orcid.org/0000-0002-8049-1369.

${ }^{4}$ Doutoranda em Ciências pela Faculdade de Saúde Pública - USP. Pesquisadora do grupo Micropolítica e saúde (FSP/USP), do Laboratório de Estudos e Pesquisas em Formação e Trabalho em Saúde (LEPETS) e do Laboratório de Sensibilidades (UNIFESP). Email: harete@uol.com.br. Lattes: http://lattes.cnpq.br/0988352078487283. Orcid: http://orcid.org/0000-0002-2451-3914.

${ }^{5}$ Graduada em Psicologia na Universidade Federal de São Paulo, UNIFESP. Psicóloga com especialização na Técnica Klauss Vianna no Departamento de Linguagens do Corpo, pela Pontifícia Universidade Católica de São Paulo (PUC-SP), é pesquisadora do Laboratório de Estudos e Pesquisas em Formação e Trabalho em Saúde (LEPETS) e do Laboratório de Sensibilidades (UNIFESP). Email: rafaelacamargob@gmail.com. Lattes: http://lattes.cnpq.br/5996161435745713. Orcid: https://orcid.org/0000-0002-3524-9055.

${ }^{6}$ Doutor em Psicologia na Clínica na Pontifícia Universidade Católica de São Paulo. Professor do departamento de Saúde, Clínica e Instituições da Universidade Federal de São Paulo (UNIFESP), pesquisador do Laboratório de Estudos e Pesquisas em Formação e Trabalho em Saúde (LEPETS), do Laboratório de Sensibilidades e do Laboratório de Psicanálise. Email: sidneicazeto@uol.com.br. Lattes: http://lattes.cnpq.br/3498118188722873. Orcid: https://orcid.org/0000-0002-7481-5312.
}

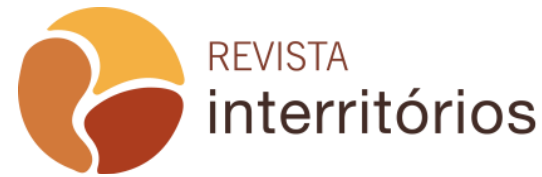

Interritórios | Revista de Educação Universidade Federal de Pernambuco, Caruaru, BRASIL | V.5 N.9 [2019] 
determinados. Algumas experiências passam tempos em um período de incubação e depois se transformam, ganham outros sentidos. Há graus e variações de pactuação, há acordos maiores, explícitos, e eles envolvem pequenas pactuações, invisíveis, sutis, mais próximas das alianças episódicas, pactos delicados que vão deslizando a sensibilidade. Este texto dá expressão a uma série de marcas que insistem em nós, tratando-se ele também de um experiência de sondagem.

Laboratório de Sensibilidades. Pactos delicados. Trabalho em saúde. Dispositivos de Formação.

\section{Sensibility pacts}

\section{ABSTRACT}

This article presents sensitive experiences related to the sensitivities laboratory of UNIFESP, also related to training and work in health. Based on narratives produced by members of GELS (sensitivities laboratory study group) it was possible to unfold experiences and investments that constitute training measures, not always with specific goals. Some experiences spend some time in incubation period and then are transformed, gaining new meaning. There are levels and variations of agreements, there are greater and explicit understandings, and they involve small agreements that are invisible, subtle, closer to episodic alliances, delicate pacts that slide the sensitivity. This text gives expression to several marks which insist on us, also meaning a survey experience.

Sensitivities laboratory. Delicate pacts. Work in health. Training measures.

\section{Alleanze sensibili}

\section{RIASSUNTO}

Questo articolo presenta esperienze sensibili relative al laboratorio di sensibilità UNIFESP, all'educazione sanitaria e al lavoro. Dalle narrazioni prodotte dai membri del gruppo di studio GELS (Sensitivity Laboratory), è stato possibile dispiegare esperienze e scommesse che costituiscono dispositivi di allenamento, non sempre con obiettivi specifici. Alcune esperienze trascorrono del tempo in un periodo di incubazione e poi si trasformano in altri significati. $\mathrm{Ci}$ sono gradi e variazioni di alleanza, ci sono accordi più ampi ed espliciti e coinvolgono piccole, invisibili, sottili alleanze, più vicine alle alleanze episodiche, patti delicati che fanno scivolare la sensibilità. Questo testo esprime una serie di segni che insistono su di noi ed è anche un'esperienza di sondaggio.

Laboratorio di sensibilità. Patti delicati. Lavoro in salute. Dispositivi di 
adestramento.

\section{RESUMEN}

\section{Pacto de lo sensible}

Este artículo presenta experiencias sensibles relacionadas con el Laboratorio de Sensibilidad de UNIFESP, con la formación y el trabajo en salud. A partir de las narrativas producidas por los miembros del GELS (Grupo de Estudio del Laboratorio de Sensibilidad), fue posible desarrollar experiencias y apuestas que constituyen dispositivos de formación, ni siempre con objetivos específicos. Algunas experiencias pasan tiempo en un período de incubación y luego se transforman en otros significados. Hay grados y variaciones de pacto, hay acuerdos más grandes y explícitos, e involucran pactos pequeños, invisibles y sutiles, más cercanos a alianzas episódicas, pactos delicados que deslizan la sensibilidad. Este texto expresa una serie de marcas que insisten en nosotros, y también es una experiencia de sondeo.

Laboratorio de Sensibilidad. Pactos Delicados. Trabajo en Salud. Dispositivos de Formación.

\section{INTRODUÇÃO}

Os feiticeiros sempre tiveram a posição anômala, na fronteira dos campos ou dos bosques. Eles assombram as fronteiras. Eles se encontram na borda do vilarejo, ou entre dois vilarejos. O importante é sua afinidade com a aliança, com o pacto, que Ihes dá um estatuto oposto ao da filiação.

Deleuze-Guattari

O que faço é juntar isso e aquilo, aqui e acolá, concentrando-me na experiência clínica, formando minhas próprias teorias e, então, depois de tudo, me interesso em descobrir de onde roubei o quê.

Winnicott

Sem um pacto não acompanhamos, não permanecemos; é preciso alguns acordos. Há graus e variações de pactuação, há acordos maiores, explícitos: sem eles não vamos aos cortiços, aos morros etc., e eles envolvem pequenas pactuações, invisíveis, sutis, mais próximas das alianças episódicas, pactos delicados que vão deslizando a sensibilidade. Tudo isso é menos voluntário ou consciente e, dá aos pequenos pactos, um estatuto distinto da filiação a uma ideologia, a uma teoria. E, a cada mínimo pacto, desliza a própria pactuação, seus limiares, fibras de sensibilidade, suas bordas. Pactos podem mobilizar gradientes e limiares de percepção. 
O grupo de estudos do Laboratório de Sensibilidades ${ }^{7}$ (GELS) reúne docentes, estudantes e egressos que continuam com as experiências pactuadas do Laboratório, que perscrutam traços de uma formação construída por caminhos diversos. Integrantes do GELS foram convidados a elaborar narrativas, experiências sensíveis que tivessem relação com a formação e/ou com o trabalho em saúde, tendo respondido ao convite os autores deste texto. As narrativas foram colocadas em um arquivo coletivo e, ao lermos o conjunto, foi possível desdobrar experiências e apostas que constituem dispositivos de formação, nem sempre com objetivos determinados. Ao longo dos anos, vamos nos encontrando de novo com alguns experimentos e seus efeitos. Algumas experiências passam tempos em um período de incubação e depois se transformam, ganham outros sentidos. Este texto dá expressão à uma série de marcas que insistem em nós, tratando-se também ele de uma experiência, de uma sondagem.

Das narrativas foram produzidos tópicos que destacaram um conjunto de temas. Em seguida, estes temas foram organizados em um roteiro, que colocou as narrativas em sequência e sinalizou a discussão a ser feita em relação a elas. A etapa seguinte foi redigir esta discussão. Enquanto as narrativas constituíram-se em relatos impactantes e pactos singulares, o texto final pretendeu subverter particularismos, montando-as como peças embaralhadas em um mosaico. A ideia foi costurar situações singulares com palavras coletivas.

\section{Sensíveis, estranhas experiências do comum}

Estranhas situações, contato com estranhos. As impressões dos outros não têm bom acolhimento inicial, via de regra. Elas perturbam, desassossegam. A não ser que já sejam aquelas domesticadas, apaziguadas, reconhecidas, que perderam seu potencial de desestabilização e parecem reassegurar a permanência do mesmo. Caso contrário, incômodo, angústia, solidão. As identidades ficam ameaçadas, os nexos, fragilizados. Nada assegura mais o que parecia tão bem assentado, e têm-se a sensação desconcertante de que a realidade poderia ser aquela outra, na qual, até então, não existíamos. Nada é tão perigoso quanto encontrar alguém:

Éramos quarenta professores reunidos, o primeiro dia dos novos professores, o primeiro dia do campus. Conversamos rapidamente e percebi que não tínhamos interesse pelos

\footnotetext{
${ }^{7}$ O Laboratório de Sensibilidades, inaugurado em fevereiro de 2007 no campus Baixada Santista da Unifesp, tem como objetivo ampliar as referências estéticas e as possibilidades de experimentação no campo sensível.
} 
mesmos autores, nunca li nada do que ele mais gostava, não tínhamos ideias claras e termos em comum. Também com os outros professores, não entendia nada do que diziam, mesmo quando alguém me perguntou: Quer uma bala? Não conseguia entender. Nos dias seguintes falei com ele no café, me perguntou sobre minha tese, falei que era o problema do esgotamento, do cansaço, do grande cansaço contemporâneo. Era um assunto difícil, talvez abstrato, ele podia não estar concordando, e disse: - conta mais. Parecia entender o que eu dizia. Ele foi quase ignorado quando falou para todos sobre um pesquisador de saúde pública da Unicamp e que podia ajudar a pensar o que iríamos fazer no novo projeto pedagógico, e, aí eu disse: - Sim, sim, diga mais. Agora sei, teríamos muito a fazer e a nos dizer, por vários anos, tinha coisas a lhe dizer e ele a mim, algo que entrevia. Não era nada harmonioso, não éramos da mesma turma, os sanitaristas, os lacanianos, os santistas, os freudianos, os marxistas etc. (DEJOURS, 1998).

Em uma conversa, às vezes, o que conta não é tanto o que se diz, mas o corte e a sequência, a marcação de sequências, e o que interessa é escutar as sequências de uma espécie de música, e, frequentemente, o que se diz no interior dela não tem importância maior (PAIN, 1985). Na situação acima havia uma estranha sonoridade, uma base sensível sem base, sinais sutis, muita gente e nada disso foi demasiadamente consciente; deu-se a exposição e também seleção do que era interessante. Isso poderia ser especialmente explorado no âmbito da formação em saúde.

Um outro viés é que o mal-estar com o estranho esteja no fato de que não se trata, tanto quanto parece, de uma diferença irredutível entre um e outros, mas, paradoxalmente, de que haveria, no estranho, algo de familiar que se resiste em conhecer (FREUD, 1919/2010). Se a vida implica na seleção de impressões e, consequentemente, em exclusões contínuas, o excluído reaparece, insistente e inconformado. Dar-lhe espaço em nosso mundo é uma decisão política de fronteira.

Eu estava passando no corredor da unidade de saúde e ela veio na minha direção falando:

- não consegui trazer a menina.

Carregava nos braços um bebê que tinha cerca de um mês de idade, e continuou:

- o meu marido não quer me deixar sair de casa. Não tá certo, né?

Eu não a conhecia e nunca tinha atendido a sua filha. Ela estava agitada.

- ele me amarra com as fitas. Foi desde que nasceu este menino. Depois que cheguei do hospital, ele tá fazendo isso. Não tá certo, né? Ele não me bate não, me amarra com as fitas de cabelo. Me amarra assim, ó. E mostrava as mãos cruzadas. Ali no corredor, seguiu falando dos filhos, da vacina, da irmã, da consulta que perdeu, da escola, do marido que a amarrava na cama. Vários fragmentos. 
Perguntei onde morava. Ela me mostrou o cartão da unidade. Consegui pegar o seu prontuário e percebi que ela havia me confundido com a fonoaudióloga que atendia sua filha. Precisava compreender melhor o que estava acontecendo e combinei de ir no dia seguinte na sua casa para conversar mais.

Depois desse encontro, procurei os profissionais que a atendiam na unidade. As informações eram poucas... Ela se chamava Débora e diziam ter certo "rebaixamento cognitivo". Seu marido era carroceiro. Tinha uma irmã que morava perto e a ajudava. Sua filha de sete anos havia sido encaminhada para atendimento com a fono por dificuldades de aprendizagem. Informações também eram fragmentadas, porém sem nenhuma referência anterior de violência.

Fomos à sua casa, que ficava na favela. Foram muitas conversas: com a irmã, com os vizinhos, professores. Fomos juntando as peças. Tratava-se de uma grave situação de violência: o marido violentava sexualmente os seus filhos. Ela precisava da confirmação de que não estava certo o que 0 marido fazia, pois sua irmã dizia que ele era um bom homem que cuidava dela e dos filhos.

Seu atendimento envolveu vários profissionais da unidade, lideranças da favela, profissionais da escola, da assistência social, conselho tutelar, entre outros. Encontrei-me várias vezes com Débora. Ela ainda me confundia com a fono. Parecia saber que tínhamos, eu e a fono, certa sensibilidade em comum.

Eis como um engano, ao invés de ser corrigido, foi utilizado como um acesso. A história poderia ter sido diferente: "acho que você está me confundindo com outra pessoa que the atendeu. Vou ver quem foi e the encaminhar a ela". Ao invés, aquela conversa estranha chamou a atenção. Pode-se rejeitar os desvios da rotina como incômodos a serem reorientados, e frequentemente é o que ocorre, sobretudo no trabalho em saúde, em que se está premido pelo tempo. Às vezes, porém, ocorre uma tolerância com o imprevisto que interrompe a tarefa e desencadeia uma sondagem. Algo se entreviu, ali, no cruzamento daqueles caminhos. Alguém pôde sintonizar-se com aquele apelo desconcertado. Era mesmo uma confusão de identidades, só que outra: o marido não era um bom homem que cuidava dela e dos filhos. Débora teria percebido ecos entre as profissionais, como sugere a narrativa, e tomando-as como braços de um corpo comum? Talvez, mas tentando fazer o tempo descontinuar para que sua perturbação pudesse ser percebida.

As faixas de frequências com que se pactua com outros são diversas. $O$ interessante é encontrar a possibilidade desta equalização no predomínio da diferença. De certo modo, o que pode ser instigante é exatamente a diferença, mas é como se ela não pudesse ser apreciada, senão por meio de algum fio de 
conexão que é também fio de metamorfose ${ }^{8}$. Em sua ausência, seria um diálogo de surdos; com ele, o tímpano consegue vibrar, reverberando e demandando sons. Mas como criar condições para ouvi-los?

Conviver com o silêncio tratava-se de uma nova experiência que emergia nos encontros da Oficina do Silêncio no Laboratório de Sensibilidades. Silêncio, é assim que nomeamos o tempo em que ninguém fala. Um tempo em que se escuta. E se escuta muita coisa. Conforme o silêncio vai silenciando vai se ouvindo outras coisas. Não se trata de qualquer silêncio. Fizemos oficinas do silêncio no Laboratório de Sensibilidades: proposta de ficar parado e quieto, sem dormir, em qualquer posição corporal, sem fazer nada por 30 minutos. Não era meditação, não havia metas de alcançar algo; não era preciso fechar os olhos. A ideia era parar e silenciar em companhia. Nas edições que aconteceram, o que percebi foi um imenso barulho; a falta de foco possibilitava ouvir a cacofonia do instante: sons diversos, sobrepostos, não equalizados. Dispersão, fuga de ideia, caos. Era como se a disciplina da atenção tivesse sido suspensa, a campainha do final da aula tivesse tocado e a molecada houvesse saído em disparada gritando.

Há um exercício de abrir-se para qualquer silêncio, dando espaço. Há qualidades de silêncio, uma postura ativa, e silêncios sem qualidade, para nada, silêncios de habitar juntos sem abandonar a presença, juntos sustentando a convivência de estar em silêncio, silêncios de abandono de si, silêncio qualquer, comum. No projeto de extensão Literatura e Clínica também se partilhava silêncios longos, muitas vezes, sem prescrição. Havia silêncio para os barulhos do texto pertencerem ao encontro, coexistirem. Nestes encontros no Laboratório de Sensibilidades, do Literatura e Clínica, da Oficina do Silêncio e do Clube dos Saberes ia-se formando uma consistência experiencial, em práticas que arriscavam outros modos de estar junto e de partilhar, mesmo que de forma episódica, experiências do sensível ${ }^{9}$.

Há diversos aspectos a se considerar nestas experiências. Um deles: o silêncio auto-imposto promovia uma espécie de ascese. Reduzia-se um

\footnotetext{
${ }^{8}$ Neste caso conexões rebeldes a fios condutores excessivamente categóricos. Parece que elas implicam quebradiços segmentos de fios de metamorfose sensíveis às circunstâncias das ocorrências, ao que abre jogos de forças, ao que exala tensões etc." Orlandi, Luiz.

Procedimentos expressivos de um caso que já é, ele próprio, expressão de um mundo. Disponível em: https://laboratoriodesensibilidades.wordpress.com/2017/04/24/procedimentosexpressivos-de-um-caso-que-ja-e-ele-proprio-expressao-de-um-mundo-do-ponto-de-vista-doproblema-que-nos-ocupa-o-dos-procedimentos-expressivos-de-um-caso-essa-posicao-d/ Acesso em 12/07/2018.

${ }^{9}$ O projeto de extensão Literatura e Clínica ocorreu entre 2006 e 2010, promovendo experimentações de leitura de obras literárias. O Clube dos Saberes, também projeto de extensão, constituiu-se de uma estratégia de circulação de conhecimentos distribuídos entre os integrantes da universidade e da comunidade; manteve-se de 2007 a 2011. Todos ocorreram/ocorrem (pois episodicamente retornam) no campus Baixada Santista da Unifesp.
}

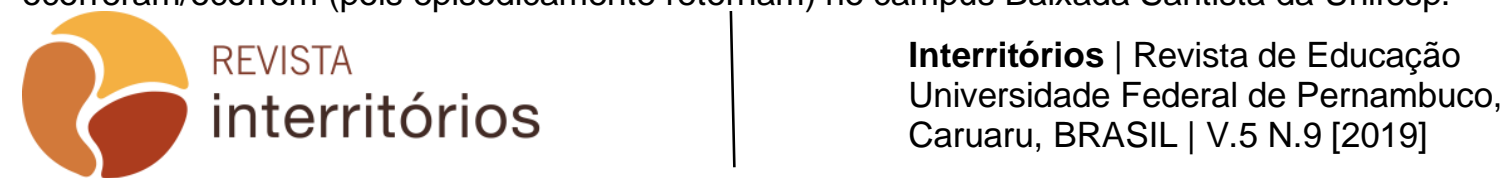


barulho para ouvir outro, fechava-se um canal para abrir novos. Ao que parece, a percepção do sensível depende desta alternância: quem, no momento, ganha a cena, e quem, em contraste, sai dela. Alguma insensibilidade parece necessária para a própria sensibilidade acontecer. Mas não há exigência de que tal distribuição seja fixa, que os ocultados e os escolhidos sejam sempre os mesmos. Havendo oportunidade, é possível exercitar o trânsito pela combinatória de positivos-negativos.

As oficinas com as crianças aconteciam no andar de cima de um sobrado ocupado pela Associação de Cortiços. Uma escada de madeira com alguns degraus danificados dava acesso ao espaço que usávamos: uma sala grande, com dois janelões cujos vidros tinham quebrado pelo crepitar dos trens que passavam ao lado, restando ainda cacos, alguns com pontas. Livros doados empilhavam-se numa reentrância da sala. Baratas e ratos por vezes davam sinais. Havia uma pia com torneira, mas não sabíamos se a água vinha de alguma caixa d'água, e como ela estaria. As crianças, algumas carregando bebês, subiam correndo a escada, cheias de energia. Não se incomodavam com o ambiente. Nós, da universidade, que estranhávamos tudo, depois de algum tempo também estávamos temporariamente insensibilizados e concentrados nas crianças e brincadeiras.

Para operar essas mudanças de registro do sensível era preciso deslocar-se, sair do ambiente conhecido, caminhar por ruas não habituais, expor-se a impressões diversas. Há algo de atraente nestas pequenas viagens: o conhecido assegura tanto quanto entedia. Uma escultura de Rodin, chamada "O homem que anda", indica o fascínio sensível do movimento. Só as pernas e pés compõem a escultura. François Tosquelles em entrevista a Pain (1985), diz que, quando andamos pelo mundo, o que conta não é a cabeça, são os pés: você tem que saber onde põe os pés; são eles os grandes leitores do livro do mundo, da geografia. Não é sobre a cabeça que se anda, os pés são o lugar da recepção. Trata-se de ficar de pé, de fazer uma distribuição do tônus, para ir a algum lugar, mas é com os pés que se vai, não com a cabeça. E dizia: "Vocês pensam com a cabeça quando é preciso pensar com os pés" (OURY, 2012, p. $10)$.

Observar o caminhar e pisadas até a casa dos narradores ${ }^{10}$ nos permitia aprender sobre caminhar e chegar. $O$ ritmo passava a ser partilhado, então as agentes comunitárias de saúde e nós passávamos a pisar junto. O início do encontro já

\footnotetext{
${ }^{10}$ Num dos módulos chamado "Encontros e produção de narrativas", do eixo curricular "Trabalho em Saúde", que são comuns aos cursos de saúde do campus Baixada Santista da Unifesp, duplas de alunos de diferentes áreas colhem as histórias de vida e saúde de moradores de regiões vulneráveis da cidade, indo às suas casas durante um semestre letivo, e, ao final, entregam-Ihes suas narrativas na forma de texto e/ou de imagens.
} 
se dava ali, uma prévia para permitir fazer encontrar os tempos. Parecia um exercício de desacelerar o corpo de estudantes, jovens, que se mexiam demais para adentrar a casa das pessoas. Casas pequenas geralmente. Essa desaceleração nos abria, de certo modo, para acolher as delicadezas, para acolher histórias que rasgavam muitas vezes as vidas dos que narravam. Rasgavam a nós. O retorno das casas até a unidade básica retomava o ritmo da caminhada de ida, as pisadas eram nossas agora, que precisavam daquela sequência para retornar com todas as histórias que agora também eram nossas. Encontrávamos outras duplas e trios no caminho, todos estrangeiros àqueles territórios, caminhávamos pausado tal como o professor que nos guiou na primeira ida. Aqueles passos pertenciam a nós agora.

Outro aspecto a se considerar diz respeito ao esforço de transformar a experiência disruptiva do sensível em um acontecimento de base comum. Se não suportamos a prisão da origem, se as expedições acabam por nos arrebatar, se aceitamos todos os desconfortos do sensível, parece ser pela expectativa de encontrar algum ponto que nos recoloque em conexão, qual porto de viagem. E novamente partir. Assim, o sensível em comum seria uma espécie de encontro no espaço-tempo, tão forte quanto volátil. Uma fortuna a ser permanentemente reconquistada.

\section{Sensível, limiares do encontro sem nome, do tolerável e do intolerável}

Eles haviam criado adereços na oficina de chapéus de boibumbá. Fitas coloridas, estrelas, luas, lantejoulas, glitter. Cada um com o chapéu que quis fazer. Na cabeça. Nas mãos. Muitas atividades na vielada cultural na periferia e as crianças de uma ocupação de moradia. Tudo molecada. Da ocupa e da quebrada. Sentados no chão, resolveram mexer na água parada da sarjeta. Começaram a bater seus pés calçados de chinelos ou tênis. Um menino que já estava arrancando umas fitas do seu chapéu, resolveu chafurdá-las naquela sujeira. Impossível continuar em silêncio. A saúde, imperiosa, higienista, explica o risco de doença, o que poderia haver naquela água. A repreensão de terem estragado o chapéu que eles mesmos fizeram.

"É muito importante não termos medo da sujidade", frase da bailarina Vera Mantero (1998, p. 4), que desdobra-se em possíveis difíceis de sustentar. Havia algo ali, naquela molecada, naquela margem, que não se alcançou na hora. Do não-saber ao desistir: eles ignoraram o apelo solenemente, destruíram o chapéu, toda violência naquela brincadeira na margem. Da margem. À margem. Sempre de fora. 
O sensível não parece mesmo muito afeito à limpeza. Antes, tende à mistura, às afinidades heterogêneas. É difícil sustentá-lo na pureza, em ambientes assépticos e estéreis, pois o contágio parece ser o principal meio de sua transmissão. A boa forma não seria um melhor operador do sensível do que as demais, ainda que costume ser apresentada como tal, por ser mais bem acabada, melhor resolvida. Mas, seja ela ou outras, conforme sua intensidade, transtorna, exigindo recursos significativos para lhe suportar.

Era o dia de inauguração do Laboratório de Sensibilidades ${ }^{11}$. Neste dia um rapaz faz uma performance. Durante a performance, uma variação de efeitos ia se dando, e, como pode se notar, ainda estão em processo. Tomarei apenas duas linhas para destacar: durante a performance alguns dos incômodos foram produzidos diante da descamação de um peixe morto, que produziu um cheiro no ambiente; eu inclusive me incomodei um tanto com ele. O outro se deu quando o rapaz, nos fins da performance, disse para nomearmos 0 objeto/trabalho produzido naquele dia, que só terminaria após nomearmos o rebento produzido ali, disse algo que me deixou com um enorme ponto de interrogação: "o nome a gente dá apenas no final, geralmente...". Juntos escolhemos o nome para o trabalho, que foi muito além do objeto produzido: "sensibilidade acadêmica". Afinal, o que seria essa sensibilidade acadêmica, atravessada pela capacidade de suportar os inomináveis?

Uma informação adicional a esta performance que merece ser citada: 0 artista, após tirar as escamas, fazendo difundir o odor num dia de calor praiano, engessou o peixe. Assim, a escolha do nome da performance como sensibilidade acadêmica, pelos presentes, mostra a sua contradição. Que sensibilidade é possível sob uma armadura de gesso? Que flutuações são viáveis com o peso de uma massa endurecida sobre a pele? Que formas a academia impõe aos estudantes em formação?

Por outro lado, seria preciso considerar se algum tipo de mediação não seria necessária para que uma experiência sensível se dê. Expostos às intensidades, à alteridade radical, não resistiríamos. Poderíamos tomar a sensibilidade como uma abertura do organismo a certos mundos. Ora, as forças de determinados mundos são mais intensas e violentas do que qualquer organismo aguentaria se não fossem seus filtros, que atenuam esta exposição. Os órgãos dos sentidos seriam como que pequenas janelas que capturam uma quantidade possível de excitação (FREUD, 1920/2010). Mas toda entrada de estímulos aumenta a tensão interna e isto pode tender ao incremento da angústia.

${ }^{11}$ A descrição da performance pode ser encontrada em https://laboratoriodesensibilidades.wordpress.com/2011/12/07/laboratorio-de-sensibilidades2007-primeiro-dia-4/ Acesso em 07/07/2018.

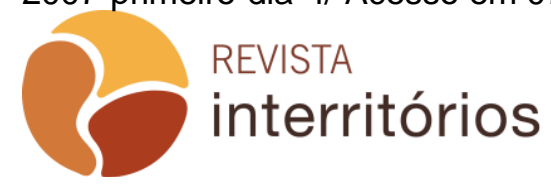

Interritórios | Revista de Educação

Universidade Federal de Pernambuco, Caruaru, BRASIL | V.5 N.9 [2019] 
Em relato de viagem de 1837, após visitar a basílica de Santa Croce, em Firenze, e contemplar os afrescos de Giotto, Stendhal descreveu uma série de sintomas que um século e meio depois foram chamados de "síndrome de Stendhal" ou "síndrome de Firenzi" pela psiquiatra italiana Grazielle Magherini (HADDAD; HADDAD, 1995). Ao que parece, aceleração do ritmo cardíaco, vertigens, desmaio, confusão e alucinações, são provocados amiúde pela exposição de apreciadores a obras de arte. Deste ponto de vista, ampliar o sensível implica em sustentar maior perturbação e dali produzir algo que possa dar contorno à experiência.

Um tempo depois de ter tido a oportunidade de conversar com ela, fiquei sabendo que optar por escutá-la foi uma disputa. Aparecida morava numa casa simples com seu companheiro dito alcoolista. Estava paraplégica após cair do muro, conforme nos contou ao longo de nossas conversas. Há quem tivesse a suspeita de que teria sido o companheiro que a empurrou, algo que ela nunca nos disse. Sua casa, principalmente no primeiro encontro, tinha um cheiro forte, de mijo. Aparecida não era apoiada sempre nos cuidados da casa e de si, o que parecia contribuir para que o cheiro de sua residência fosse aquele. Ela comentava do seu desejo de fazer fisioterapia, foram várias tentativas, mas algo faltou: alguém que a tirasse de casa e lhe conduzisse até o local próximo onde a ambulância a pegaria. Após muito hesitar, decidi ir lá numa madrugada e ajudar a carregá-la. Conseguimos, mas ficamos no ponto esperando a ambulância, que não chegou. Após este episódio não mais investi naquilo. No final das conversas entreguei sua narrativa de vida, tarefa que aquele módulo, que nos conectava a ela, exigia. $\mathrm{Na}$ narrativa havia um fragmento de poesia do Drummond, no qual o trecho "fabrico um elefante com meus poucos recursos", parecia dizer algo de sua vida. Ela, já mais alegre e receptiva, se emocionou bastante, disse neste dia que tinha filhos e que não os via há muitos anos, e, tinha saudades.

Nas cenas, cheiros, de todos os tipos, inclusive tipos de cheiros que ao percebermos tendemos rapidamente a nomear como "cheiro a ser evitado", modificado, a ser limpo. Nenhum desses cheiros ${ }^{12}$ foi confortável para quem,

\footnotetext{
12 Ainda que no Brasil o enunciado higienista: "pobre, mas limpinho", persista, Alain Corbin sublinha que as camadas populares não deixaram de inverter essa representação reforçando sua aliança com o podre. No século XVIII e XIX se recusam a adotar a higiene, procurando sempre afirmar sua posição antinômica à burguesia. Os antigos costumes de eliminar gases em público, muitas vezes como forma de exibicionismo, ou de fazer batalhas de excrementos rua abaixo durante o Carnaval, adquiriram um significado novo em face dos desmaios e enjôos provocados nas famílias de seus opressores. Mas o caráter lúdico dessa resistência não sobreviveria ao influxo das práticas aprendidas nos quartéis e nas escolas (sociedade disciplinar). Pouco a pouco as comodidades da vida promíscua serão abolidas, dando lugar à desodorização dos ambientes que se completará na segunda metade do Século XIX. Cheiros que antes passavam quase desapercebidos a partir da segunda metade do século XVIII tornam-se incômodos e, mais que isso, começam a provocar horror. Acerca destas questões ver: CORBIN, Alain . Saberes e odores : o olfato e o imaginário social nos séculos XVIII e XIX 
afinal, também nasceu nessa época em que alguns cheiros não são toleráveis (CORBIN, 1987).

No alojamento da prefeitura, uma senhora que estava há tempos ensimesmada e pouco disponível para conversas, fala de seus percursos, revezando com leitura de poesias. Poetisa o bairro e acontecimentos de sua vida. Poetisa para personalidades que admira. Poetisa para o estudante que fará sua narrativa, é dia do aniversário dele. Enquanto isso, numa palafita, uma estudante se esforça para manter a atenção nas falas de outra senhora. O cheiro do mangue passeia por todos os lados. A estudante diz ter dificuldade em lidar com cheiros fortes. De súbito olha para o lado e percebe que a criança, que ficava subindo e descendo do seu colo, defecou no chão. Terminado o encontro solicita supervisão.

Todavia, sobretudo nas duas últimas cenas, os cheiros e outras coisas eram, ao narrador, familiares: as casas, pessoas e seus cheiros lembravam pessoas de sua família. Ele próprio já havia morado em condições mais precárias que aquelas e convivido com cheiros ainda menos toleráveis, muito cedo.

Vê-se que sensibilidades são construídas e desfeitas, no encontro com mundos. Na sociedade asséptica, de disseminação dos ricos e riscos a toda esfera da vida, não é automático sustentar encontros e acompanhar vidas sem sobrevalorizar determinados cheiros. A possibilidade de estar em relação depende de alguma elasticidade do sensível, de afetar e ser afetado.

\section{Sensível em formação}

Não raramente, os efeitos das experimentações e práticas produzidas com o Laboratório de Sensibilidades transversalizam outras experiências da formação, prolongando-se para ações fora da universidade ${ }^{13}$. São

São Paulo: Companhia das Letras, 1987, e, o filme O Perfume do diretor Tom Tykwer (2006), disponíveis em:https://laboratoriodesensibilidades.wordpress.com/2018/03/09/e-historica-aabrupta-reducao-de-tolerancia-aos-odores-leia-corbin-alain-saberes-e-odores-sao-paulo-ciadas-letras-1987-livro-esgotado-em-pdf-abaixo-e-filme-perfume-corbin-lembra-q/ Acesso em 07/07/2018.

${ }^{13} \mathrm{Na}$ Universidade Federal de São Paulo, campus Baixada Santista (UNIFESP-BS), no Instituto de Saúde e Sociedade, o Eixo Trabalho em Saúde (TS) mescla estudantes dos diversos cursos (Educação Física, Nutrição, Fisioterapia, Psicologia, Terapia Ocupacional e Serviço Social) e docentes de diferentes áreas disciplinares e profissionais. Este eixo percorre os três primeiros anos da graduação com módulos semestrais que têm como perspectiva expor os estudantes a experiências de cuidado em diferentes regiões da cidade. Ver Capozzolo AA, Casetto SJ, Henz AO, organizadores. Clínica Comum: itinerários de uma formação em saúde. São Paulo: Hucitec, 2013. Também neste campus da Unifesp ocorrem estágios e diversos projetos de extensão em conexão com os grupos que vivem em diferentes territórios da cidade (cortiços, morros, palafitas).

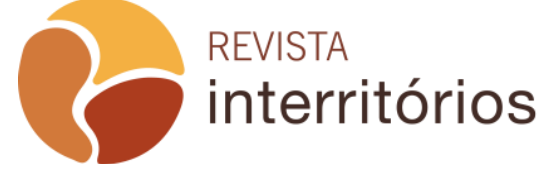

Interritórios | Revista de Educação

Universidade Federal de Pernambuco, Caruaru, BRASIL | V.5 N.9 [2019] 
investimentos de diversas ordens, exercícios e implicações distintas, como acontece no fragmento do Relatório de Estágio abaixo:

Certo dia os estudantes decidiram conversar com aquela favela que tanto produzira inquietações de diversos tipos. Nesse exercício ocupam e são ocupados por limiares de uma polifonia que parece emanar daquele território em seus processos de produção e desmontagens:

Favela: Eu tenho habitantes... gente de todo tipo, de tudo quanto é canto do país, boa parte vem lá de cima: Norte, Nordeste... e tem gente que é de outros cantos da cidade, e veio se acomodá por aqui...

Estudantes: Por quê?

Favela: Vixi, menino, muitos motivos, cada um tem sua história né... Tem gente que veio há muito tempo, por causa de dificuldade lá onde eles tavam: fome, sede, desemprego... uma dificuldade só... a maioria deixô família prá trás... Tem gente que veio porque aqui era oportunidade melhor, sabe, estavam até bem lá na terra delas... acho, mas queriam melhorar mais as condição, sabe... E tem gente que veio prá cá por causa de uma daquelas coisas que deixa as pessoas sem casa: incêndio, desocupação...

Estudantes: Várias favelas pegam fogo aqui nesta cidade. E como são as casas daqui?

Favela: Pois é menino, aqui tem casa de tudo quanto é jeito: Tem os predinhos, as casa de alvenaria, as casa de madeira, as palafitas...Olha tem as ruas também: ruas de terra, de asfalto, becos, becos de madeira. Aqueles lá das palafita, sabe... a prefeitura de vez enquando manda trocá umas madeira, outras vezes é o povo daqui mesmo que conserta a coisa, porque num dá prá ficar esperando, pode acontecer acidente, caí gente no mangue, principalmente as crianças...

Estudantes: fala mais dessa coisa aí, parece interessante.

Favela: Olha, essa região é a região das palafitas, é um lugar onde tem as casas de madeira, em cima do mangue, com vista prô mangue sabe, prá natureza...

Palafita: Logo abaixo, no escuro da água salobra, caranguejos e peixes. Reflexo dos alicerces, movimento do lixo que se agita acompanhando o ritmo das águas. Muitos dizem que não deveria estar ali. Outros dizem que o lixo ajuda a manter os alicerces, ajuda a não cair.

Alguém pergunta: É verdade?

Palafita (mais palafita, elemental): Não sei. Poluição das empresas, das gentes, na água. À frente, becos, crianças, acompanhadas de irmãos e adultos. Caminho agitado. Crianças para lá, crianças para cá. Nos fundos, o mangue passando, as árvores e pássaros. Na frente, o povo... que me habita... Mas tudo é curto. Menos de dois metros, um muro. Um muro alto. É a empresa de container. Cada metro quadrado ali é caro, o local onde estou com essas várias gentes também.

Alguém pergunta: $E$ as pessoas, gostam de morar aqui?

Palafita (mais gente, antropomórfica): Olha, tem gente que gosta, tem gente que não gosta. É um lugar onde não se paga 
aluguel, né? O pessoal diz que isso facilita muitas coisas. Já tem gente que não vê a hora de saí daqui. Não gostam do local. Não gostam do lixo. Alguns não gostam nem dos vizinhos. Outros não querem sair porque já fizeram amizades e se sentem bem, entende?

As circunstâncias em que ocorre o Laboratório de Sensibilidades, os módulos do eixo Trabalho em Saúde e os estágios em morros, cortiços e palafitas, têm implicado em operar com a condição de fragilidade. Não se trata de falta em relação ao modelo idealizado que sempre nos escaparia: nossa aposta é que mínimos pactos sensíveis, com suas fragilidades, abram margens de manobra e possam ser uma espécie de desvio no jogo do modelo e da falta.

Nessas ambiências, consideramos que os engendramentos do Laboratório de Sensibilidades em gestos, interferências e pactos de formação, ao contrário de levar ao campo a luz da universidade e da saúde, em cada encontro e nos dispositivos em que se enreda, opera na tentativa de subverter essa modalidade viril. Os contornos de uma prática adequada em saúde se veem desmanchados em meio a esses esgarçamentos e tropeços. Enfim, há pactos não controlados que sucedem à revelia, pelas costas, quando já estamos exauridos, quando algo já caducou, quando saímos da linha - num limite entre a potência e a impotência.

Nesse trânsito errático, nas pactuações sensíveis, foram necessários deslocamentos em relação à formação centrada em sala de aula, com muito investimento e negociações com professores e serviços de saúde e assistência social, para atender e constituir algumas demandas. Por exemplo, com o privilégio da ação em campo em relação às teorias, que são oferecidas posteriormente às atividades no campo, bem como encontrar conceitos à altura das experiências.

\footnotetext{
Ao final da conversa todos vão saindo, enquanto uma estudante permanece sentada com olhar fixo, sozinha, em silêncio. Momentos antes conversavam acerca dos processos que se deram nas conversações com diferentes moradores de distintas regiões durante a confecção de histórias de vida, narrativas de vida. Duas moradoras de um dos locais acompanharam a conversa. Apresentam-se. Falam do bairro e das coisas que acham interessantes e de coisas que não gostam. Falam das dificuldades que os moradores enfrentam, do tráfico, da relação com o poder público e do quanto melhorou a segurança e o tratamento da polícia aos moradores após a instalação do PCC.
}

Igualmente importante é a atenção ao impacto que esta formação gera nas andanças de campo, o que não implica na seleção de boas sensibilidades, mas na problematização persistente das dores inevitáveis. Assim, uma 
formação e aposta em pactos sensíveis procura dar espaço às desestabilizações, manejando com as precariedades e ruínas intrínsecas às vicissitudes da vida.

\section{REFERÊNCIAS}

CAPOZZOLO, A.A.; CASETTO, S.J.; HENZ, A.O. (Orgs) Clínica Comum: itinerários de uma formação em saúde. São Paulo: Hucitec, 2013.

CORBIN, A. Saberes e odores: o olfato e o imaginário social nos séculos XVIII e XIX São Paulo: Companhia das Letras, 1987.

DEJOURS, C.. Biologia, Psicanálise e Somatização. In: LICH, RM; FERRAZ, FC; ARANTES, MAA.C. (orgs.). Psicossoma II. São Paulo: Casa do Psicólogo, 1998, pp. $39-49$.

FREUD, S. O Inquietante (1919). In: História de uma neurose infantil ("O homem dos lobos"), Além do princípio do prazer e outros textos (1917-1920). São Paulo: Cia. das Letras, 1920, pp. 328-376.

FREUD, S. Além do princípio do prazer (1920). In: História de uma neurose infantil ("O homem dos lobos"), Além do princípio do prazer e outros textos (19171920). São Paulo: Cia. das Letras, 1920, pp. 161-239.

HADDAD, A.; HADDAD, G. Freud en Italie. Psychanalyse du voyage. Paris: Hachette, 1995.

LABORATÓRIO DE SENSIBILIDADES, primeiro dia. Disponível em:

https://laboratoriodesensibilidades.wordpress.com/2011/12/07/laboratorio-desensibilidades-2007-primeiro-dia-4/. Acesso em: 15/07/ 2018.

MANTERO, V. A. Desfazer-se. In Revista Elipse - Gazeta Improvável. Relógio D’água Editores Ltda, Lisboa, Portugal- 01/primavera de 1998.

ORLANDI, L. Procedimentos expressivos de um caso que já é, ele próprio, expressão de um mundo. Disponível em:

https://laboratoriodesensibilidades.wordpress.com/2017/04/24/procedimentosexpressivos-de-um-caso-que-ja-e-ele-proprio-expressao-de-um-mundo-do-ponto-devista-do-problema-que-nos-ocupa-o-dos-procedimentos-expressivos-de-um-casoessa-posicao-d/. Acesso em: 12/07/2018.

OURY, J; SIVADON, D. Conversações em La Borde. In: Cadernos de Subjetividade. Núcleo de Estudos e Pesquisas da Subjetividade do Programa de Estudos PósGraduados em Psicologia Clínica da PUC-SP, n. 12, 2012. 127p.

PAIN, F. Políticas da Loucura. Filme-documento (1985). Disponível em:https://laboratoriodesensibilidades.wordpress.com/2017/05/11/politicas-da-loucuratosquelles-com-legendas-em-portugues/. Acesso em: 07/08/2018. Data citada no artigo, 1985. 